\title{
DAMPAK PEMANENAN KAYU BERDAMPAK RENDAH TERHADAP KERUSAKAN TEGAKAN TINGGAL DI HUTAN ALAM (Studi Kasus di Areal HPH PT. Suka Jaya Makmur, Kalimantan Barat)
}

\author{
THE EFFECT OF REDUCED IMPACT LOGGING TO RESIDUAL \\ STAND DAMAGE IN THE TROPICAL NATURAL FOREST \\ (A Case Study in Forest Concession Areas of PT. Suka Jaya Makmur, West \\ Kalimantan)
}

\author{
Muhdi $^{1)}$, dan Diana Sofia Hanafiah ${ }^{2)}$ \\ 1) Departemen Kehutanan Fakultas Pertanian USU Medan \\ ${ }^{2)}$ Departemen Agronomi Fakultas Pertanian USU Medan \\ Jl. Tri Dharma Ujung No 1 Kampus USU Medan - 20154, Ph. (061) 8215170 \\ muhdisyehamad@yahoo.com
}

\begin{abstract}
The objective of the study was to know the degree of residual stand damages caused by conventional timber harvesting and reduced impact logging in natural forest. The study showed that degree of residual stand damages based on tree population in conventional timber harvesting and reduced impact logging was 33.15\% and $19.53 \%$ respectively. Based on the size injury of every individual tree, the degree of the trees damages caused by timber harvesting in conventional timber harvesting and reduced impact logging is as follow : trees heavy injury was $64.66 \%$ and $57.20 \%$, trees medium injury was $20.30 \%$ and $24.00 \%$ and trees light injury was $15.03 \%$ and $18.80 \%$ respectively. These research results indicate that conventional timber harvesting in the tropical natural forest caused heavier damage on residual stand when compared with a reduced impact logging.
\end{abstract}

Key words : conventional, reduced impact logging, residual stand damage, natural forest

\begin{abstract}
ABSTRAK
Tujuan penelitian adalah untuk mengetahui tingkat kerusakan tegakan tinggal akibat pemanenan kayu konvensional dan pemanenan kayu berdampak rendah di hutan alam. Hasil penelitian menunjukkan bahwa tingkat kerusakan tegakan tinggal akibat pemanenan kayu konvensional dan pemanenan kayu berdampak rendah berdasarkan populasi pohon masing-masing sebesar $33.15 \%$ dan $19.53 \%$. Berdasarkan tingkat keparahan keusakan pada individu pohonnya, kerusakan yang terjadi akibat pemanenan kayu konvensioal dan pemanenan kayu berdampak rendah masing-masing adalah sebagai berikut : rusak berat sebesar $64.66 \%$ dan $57.20 \%$, kerusakan sedang sebesar $20.30 \%$ dan $24.00 \%$ dan kerusakan ringan sebesar $15.03 \%$ dan $18.80 \%$. Hasil penelitian menunjukkan bahwa pemanenan kayu konvensional menyebabkan kerusakan tinggal yang lebih besar dibandingkan pemanenan kayu berdampak rendah.
\end{abstract}

Kata kunci : konvensional, pemanenan kayu berdampak rendah, tegakan tinggal, hutan alam 


\section{PENDAHULUAN}

Holmes (2000) menyatakan bahwa hak pengusahaan hutan yang pada mulanya dimaksudkan untuk mempertahankan lahan hutan sebagai hutan produksi permanen, menjadi penyebab utama degradasi hutan. Dalam survei pada lahan hutan seluas 47 juta ha yang berada di areal HPH aktif atau yang habis masa konsesinya, sekitar 30\% mengalami degradasi.

Selama ini pengelolaan hutan alam terutama pemanenan kayunya masih tidak dilakukan secara profesional, sehingga keseluruhan sistem silvikultur yang diterapkan mengalami kegagalan. Hal ini antara lain dikarenakan dalam penerapan silvikultur, belum mengintegrasikan sistem pemanenan kayu dengan sistem silvikultur. Selain itu teknik perencanaan serta pelaksanaan pemanenan kayu yang baik dan benar masih belum dipergunakan dalam pemanenan kayu di hutan alam Indonesia (Elias, 1998).

Beberapa penelitian (Elias 1997; Dykstra and Heinrich, 1996) memperlihatkan bahwa pemanenan kayu konvensional yang dilaksanakan selama ini dilakukan tanpa perencanaan yang baik, teknik pelaksanaan yang buruk dan lemahnya pengawasan yang menyebabkan menyebabkan kerusakan lingkungan yang besar. Hasil penelitian lain (Pinard et al., 1995; Sularso, 1996; Elias, 1998) menunjukkan bahwa kerusakan lingkungan akibat pemanenan kayu yang berwawasan lingkungan mampu mengurangi kerusakan. Pemanenan kayu berwawasan lingkungan ini dilaksanakan dengan perencanaan pemanenan kayu yang baik, pelaksanaan pemanenan yang terkendali dan pengawasan yang ketat selama kegiatan pemanenan kayu.

Indikator pengelolaan yang lestari adalah dampak kerusakan yang ditimbulkan selama kegiatan pemanenan kayu yang rendah. Pemanenan kayu yang ramah lingkungan (Reduced Impact Logging/RIL) yang menjadi indiator yang paling penting dalam pengelolaan hutan yang lestari adalah kerusakan tegakan tinggal yang rendah berupa tersedianya tegakan tinggal berjenis komersial yang cukup dan sehat.

Penelitian ini bertujuan untuk mengetahui dampak penerapan pemanenan kayu yang selama ini dilaksanakan di areal HPH (dengan teknik konvensional) dan berwawasan lingkungan (Reduced Impact Logging/RIL) di hutan alam.

\section{METODE PENELITIAN}

\section{Desain petak penelitian}

Petak penelitian terdiri atas petak pemanenan kayu dengan teknik konvensional dan petak pemanenan kayu dengan teknik RIL. Petak penelitian ini masing-masing seluas $10-15$ ha yang di dalamnya dibuat 3 (tiga) plot permanen/ pengukuran dengan ukuran masing-masing $100 \mathrm{~m}$ x $100 \mathrm{~m}$ (1 ha).

Plot-plot permanen/pengukuran diletakkan secara sistematis pada kedua petak penelitian sedemikian rupa sehingga mewakili tempat-tempat sebagai berikut : (1) Di lokasi tempat pengumpulan kayu (TPN), (2) Di lokasi jalan sarad utama dan (3) Di lokasi jalan sarad cabang (Gambar 1).

Teknik pelaksanaan pemanenan kayu konvensional

Pelaksanaannya dilaksanakan langsung oleh regu tebang dan sarad sesuai dengan yang diterapkan oleh perusahaan selama ini. Pemanenan kayu ini meliputi operasi penebangan dan penyaradan kayu.

Teknik pelaksanaan pemanenan kayu berdampak rendah (RIL)

Regu tebang dan regu sarad merupakan regu yang sama dengan pemanenan kayu konvensional, demikian pula peralatan pemanenan kayu yang digunakan. Sebelum pelaksanaan RIL dibuat perencanaan pemanenan kayu yang intensif meliputi : penentuan arah rebah, jaringan jalan sarad di atas peta dan ditandai di lapangan (Elias, 1998). Regu tebang dan regu sarad sebelum melakukan kegiatan pemanenan kayu diberi pengarahan dan bereifing terlebih dahulu, serta pada saat pelaksanaan disupervisi oleh peneliti. 


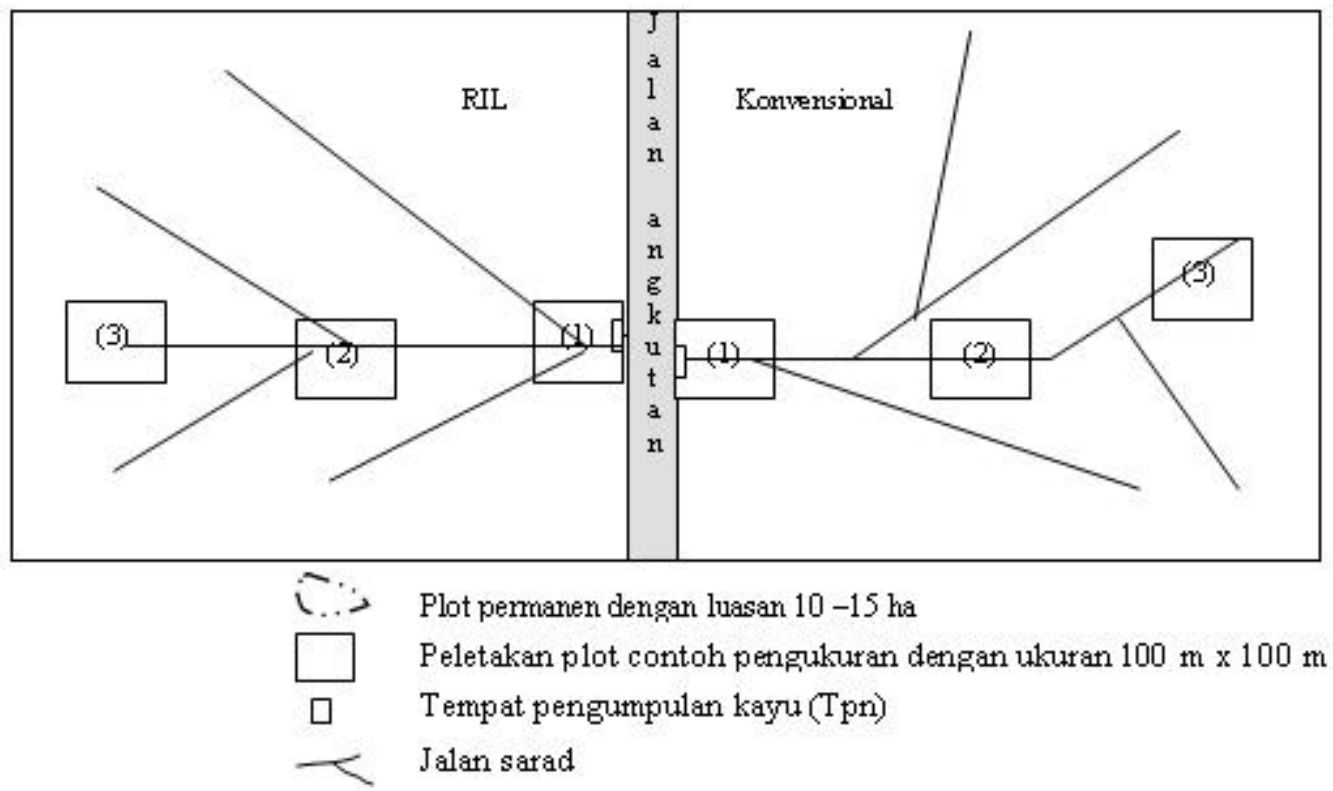

Gambar 1. Desain plot-plot permanen/pengukuran

\section{Pengumpulan data}

Data yang dikumpulkan dalam penelitian ini ada 2 macam yaitu data sekunder dan data primer. Data sekunder diperoleh melalui wawancara dan laporan-laporan yang ada. Pengumpulan data primer dilakukan melalu kegiatan pengamatan dan inventarisasi langsung di hutan pada plot permanen/pengukuran yang telah dibuat.

Inventarisasi tegakan dilakukan sebelum penebangan pada plot ukuran $100 \mathrm{~m}$ x $100 \mathrm{~m}$ (1 ha) pada petak penelitian teknik konvensional dan teknik RIL untuk melihat potensi tegakan sebelum kegiatan pemanenan kayu. Dari plot ukuran 100 $\mathrm{m} \times 100 \mathrm{~m}$ diukur dan dihitung semua jenis vegetasi tingkat tiang dan pohon secara continous strip sampling (Direktorat Jenderal Pengusahaan Hutan, 1993).

Data kerusakan tegakan yang disebabkan oleh pemanenan kayu, dikumpulkan melalui pengamatan sesudah penebangan dan penyaradan kayu. Parameter yang dicatat dan diukur adalah : nomor, jenis pohon yang rusak, diameter, tipe dan ukuran/tingkat kerusakan. Untuk melihat apakah ada perbedaan tingkat kerusakan tegakan tinggal yang diakibatkan oleh pemanenan kayu dengan teknik konvensional dan RIL dianalisis dengan analisis statistika, yakni dengan uji t.

\section{HASIL DAN PEMBAHASAN}

\section{Potensi tegakan}

Pemanenan kayu pada kedua petak berdasarkan kelompok jenis perdagangan, maka kelompok jenis non komersial (NK) mendominasi kelompok jenis lain dengan persentase rata-rata sebesar 39.27\%, kemudian kelompok jenis komersial non Dipterocarpaceae (KND) sebesar $34.56 \%$ dan kelompok jenis komersial Dipterocarpaceae (KD) 26.17\% (Gambar 2 dan $3)$.

Demikian pula dengan sebaran diameter 10 $-19 \mathrm{~cm}$ mendominasi jumlah tegakan tingkat tiang dan pohon dengan persentase rata-rata $40.12 \%$, kelas diameter 20-29 cm sebesar 39.33\%, kelas diameter $30-39 \mathrm{~cm}$ sebesar $42.92 \%$, kelas diameter 40-49 cm sebesar $33.98 \%$.

\section{Tipe kerusakan tegakan tinggal}

Besarnya kerusakan tegakan tinggal berdasarkan tipe kerusakannya sebagai akibat kegiatan penebangan kayu baik dengan teknik konvensional maupun dengan teknik RIL didominasi oleh patah tajuk dan patah batang, kemudian patah dahan, roboh, terkelupas kulit dan condong (Gambar 4). 


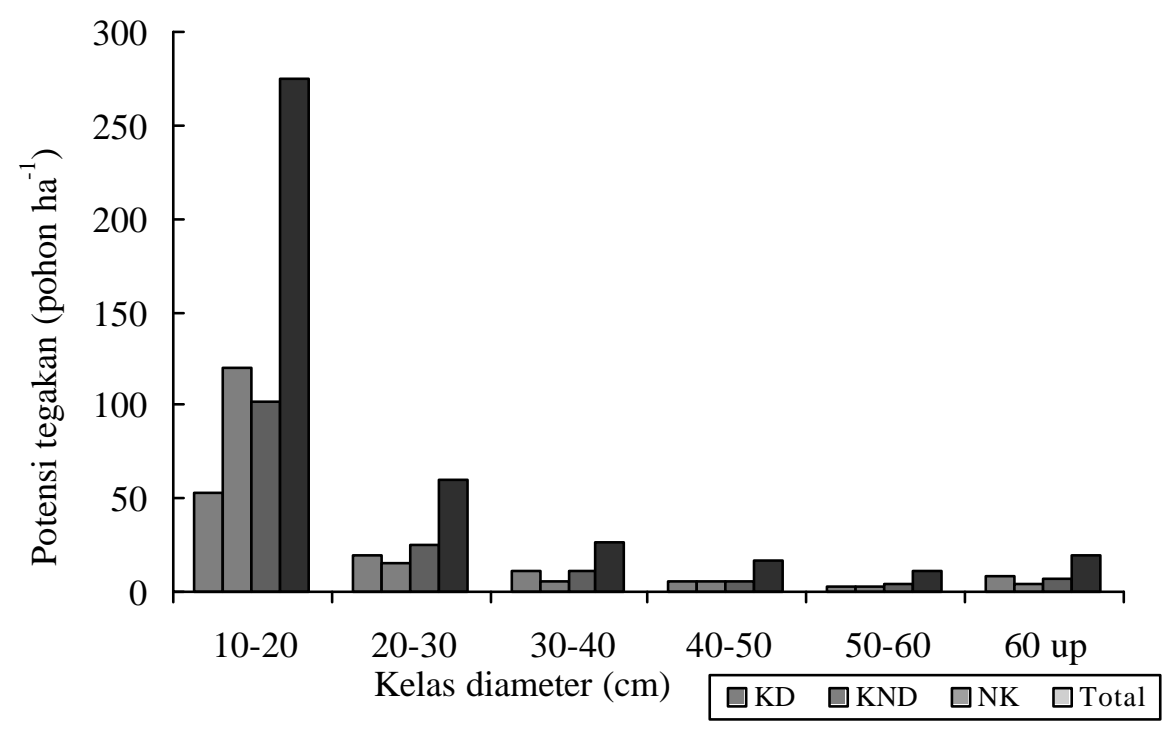

Gambar 2. Histogram potensi tegakan tingkat tiang dan pohon per kelompok jenis pada petak pemanenan kayu konvensional

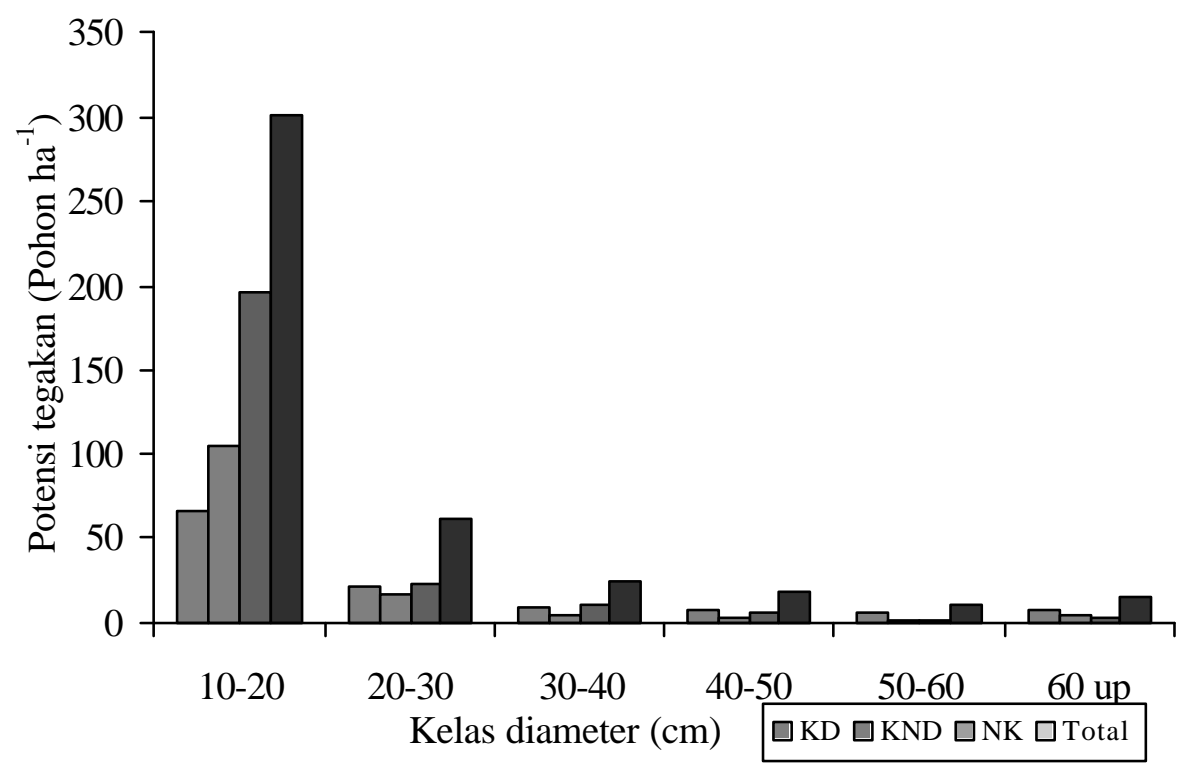

Gambar 3. Histogram potensi tegakan tingkat tiang dan pohon per kelompok jenis pada petak pemanenan kayu RIL

Jumlah rata-rata pohon rusak per ha akibat penebangan dengan teknik konvensional sebesar 35.6 pohon dimana dengan menebang 1 pohon merusakkan 5.95 pohon. Jumlah pohon yang rusak akibat kegiatan penebangan teknik RIL sebesar 22.7 pohon ha $^{-1}$ atau 1 pohon ditebang merusakkan 4.28 pohon.
Hasil tersebut menunjukkan bahwa pemanenan kayu dengan teknik RIL dapat mengurangi/menekan jumlah kerusakan tegakan tinggal tiang dan pohon sebesar 1.65 pohon haatau $27.73 \%$ dibandingkan dengan hasil yang diakibatkan kegiatan penebangan pada pemanenan kayu konvensional. 


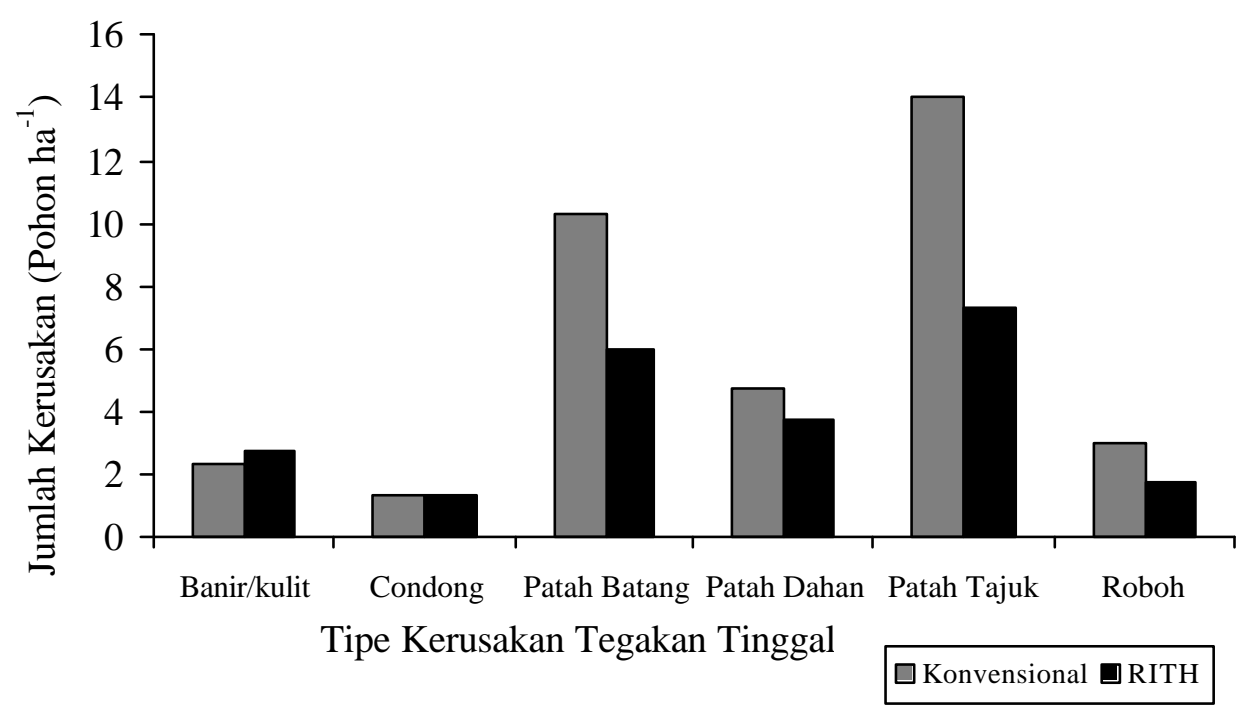

Gambar 4. Jumlah kerusakan tegakan tinggal tingkat tiang dan pohon akibat penebangan berdasarkan tipe kerusakan

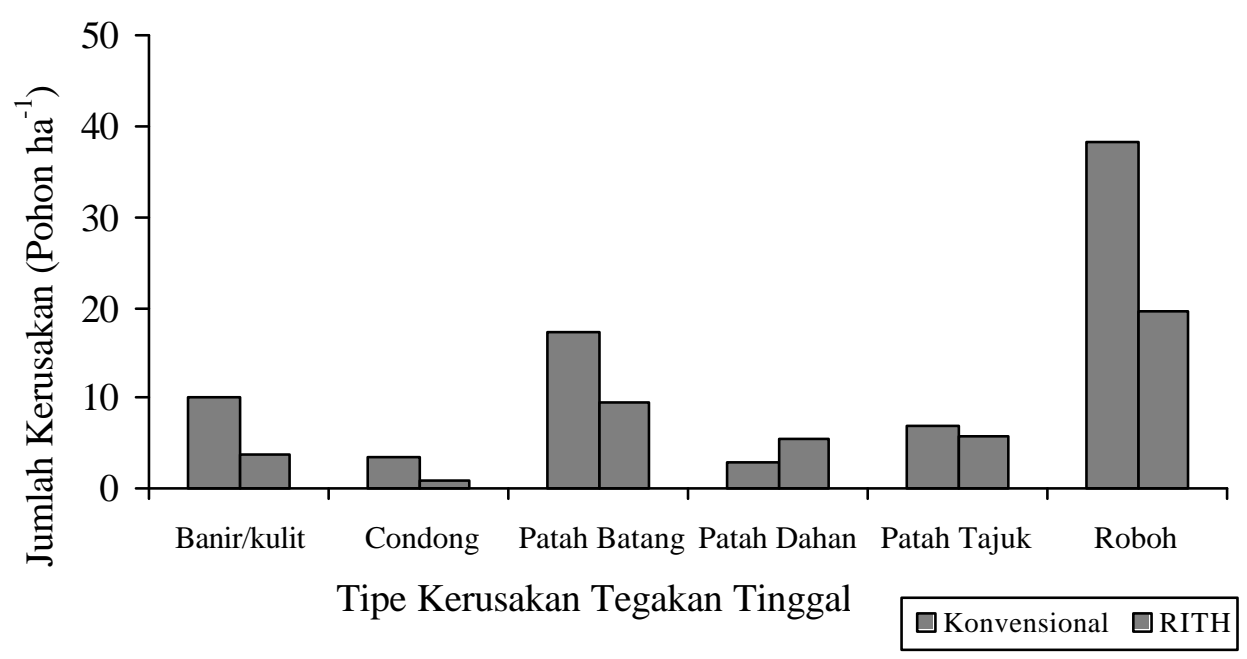

Gambar 5. Jumlah kerusakan tegakan tingkat tiang dan pohon akibat penyaradan berdasarkan tipe kerusakan.

Persentase rata-rata kerusakan tegakan tinggal tingkat tiang dan pohon akibat penyaradan teknik konvensional dan RIL didominasi oleh tipe kerusakan roboh sebesar 48.48 dan $44.07 \%$ dan patah batang sebesar 21.89 dan $20.80 \%$.

Jumlah kerusakan tingkat tiang dan pohon rusak akibat penyaradan teknik konvensional sebesar 78.6 pohon ha ${ }^{-1}$. Sebaliknya kerusakan yang diakibatkan oleh kegiatan penyaradan dengan teknik RIL sebesar 44.7 pohon ha-1 . Dari data kerusakan tersebut menunjukkan bahwa penyaradan kayu dengan teknik RIL dapat menekan/mengurangi kerusakan tegakan tinggal tingkat tiang dan pohon sebesar 4.67 pohon ha ${ }^{-1}$ atau $35.64 \%$.

Jumlah rata-rata kerusakan tegakan tingkat tiang dan pohon per hektar akibat pemanenan kayu konvensional sebesar 114.2 pohon. Adapun jumlah rata-rata kerusakan tegakan tinggal akibat pemanenan kayu RIL sebesar 67.4 pohon. Hasil tersebut menunjukkan bahwa dengan diterapkan teknik pemanenan kayu RIL dapat mengurangi/ 
menekan kerusakan tegakan tinggal tingkat tiang dan pohon sebesar 6.36 pohon $\mathrm{ha}^{-1}$ atau $33.38 \%$ dari yang dihasilkan pada petak pemanenan kayu konvensional.

\section{Tingkat kerusakan tegakan tinggal}

Tingkat kerusakan berat dalam penebangan RIL dan konvensional sebagian besar diakibatkan oleh tipe kerusakan roboh, patah batang dan patah tajuk/pucuk. Tipe kerusakan berupa patah batang dalam tingkat kerusakan berat keadaan pohonnya sudah tidak ada harapan untuk hidup atau mati dalam jangka waktu yang tidak lama. Batang mengalami patah dari 15 hingga $75 \%$ dari tinggi bebas cabang bahkan terdapat beberapa pohon yang hampir rata dengan tanah disertai ujung batang hancur. Urutan tingkat kerusakan dan perbedaan besarnya kerusakan akibat pemanenan kayu RIL dan konvensional disajikan pada Gambar 7. Besarnya tingkat kerusakan pada pemanenan kayu teknik RIL dan konvensional didominasi oleh tingkat kerusakan berat, kemudian tingkat kerusakan sedang dan tingkat kerusakan ringan (Gambar 7).

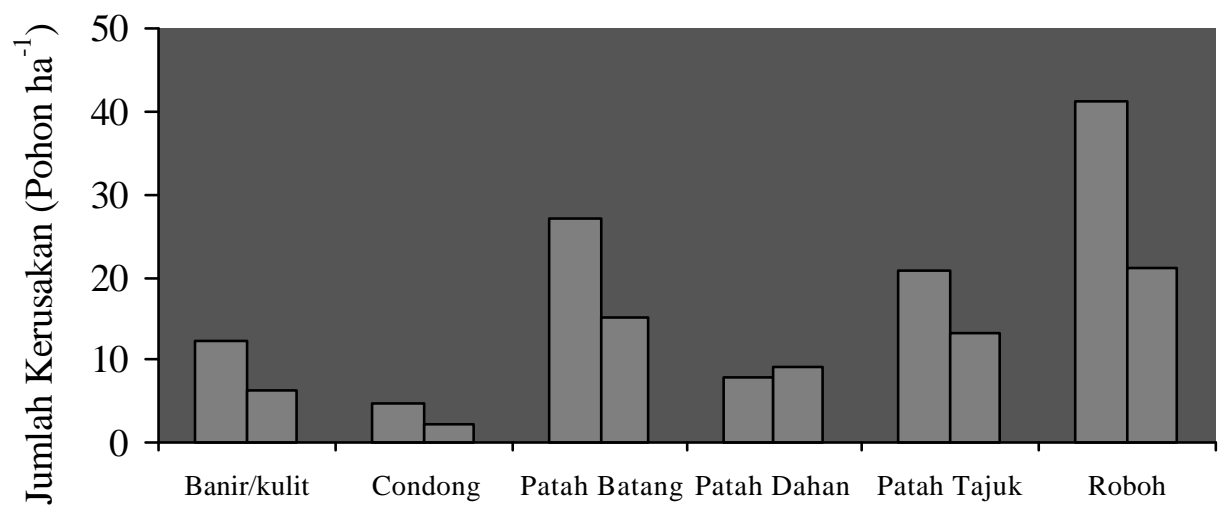

Tipe Kerusakan Tegakan Tinggal

$\square$ Konvensional $\square$ RITH

Gambar 6. Jumlah kerusakan tegakan tingkat tiang dan pohon akibat pemanenan kayu berdasarkan tipe kerusakan.

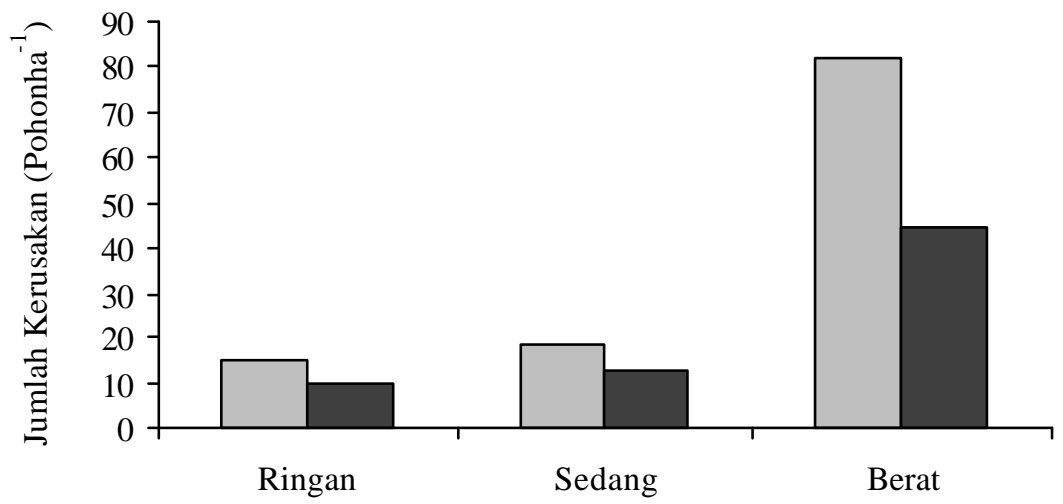

Tingkat Kerusakan

$\square$ Konvensional $\square$ RITH

Gambar 7. Histogram tingkat kerusakan berdasarkan besarnya luka pada tingkat tiang dan pohon akibat pemanenan kayu. 
Pemanenan kayu dengan menggunakan peralatan berat seperti traktor Buldozer menimbul kan kerusakan tegakan dan keterbukaan tanah lebih besar dibandingkan pemakaian sistem kabel atau menggunakan helikopter. Investasi dalam pemanenan kayu cukup besar berkisar $60-70 \%$ dari biaya pengusahaan hutan. Namun alat ini lebih mudah dan fleksibel pemakaiannya untuk memproduksi kayu dalam jumlah besar.

Pemanenan kayu teknik RIL menunjukkan persentase kerusakan rata-rata per ha sebesar $15.88 \%$. Persentase kerusakan ini termasuk dalam tingkat kerusakan ringan $(<25 \%)$, yang terdiri atas kerusakan tegakan akibat penebangan $5.32 \%$ dan penyaradan $10.48 \%$ yang termasuk dalam kriteria rusak ringan $(<25 \%)$.

Dengan demikian pemanenan kayu teknik RIL menimbulkan kerusakan tegakan pada tingkat kerusakan ringan $(<25 \%)$, sedangkan pemanenan kayu konvensional menimbulkan kerusakan tegakan pada tingkat kerusakan sedang (25 $50 \%$ ). Dengan melakukan sedikit penandan arah rebah pohon yang ditebang pada pemanean kayu RIL memperoleh hasil yang lebih baik dari pada hasil yang diperoleh pada pemanenan kayu konvensional dalam pengusahaan hutan dan berwawasan lingkungan (Sukanda, 1998).

Jumlah tegakan tinggal tingkat tiang dan pohon rata-rata setelah pemanenan kayu teknik konvensional sebesar 287.4 pohon ha ${ }^{-1}(70.44 \%)$ dengan volume $165.26 \mathrm{~m}^{3}$ (63.00\%). Sedangkan pemanenan kayu teknik RIL sebesar 358.8 pohon ha $^{-1}(83.13 \%)$ dengan volume $163.24 \mathrm{~m}^{3} \mathrm{ha}^{-1}$ (71.91\%). Tegakan tinggal di atas berasal dari berbagai sebaran diameter, bahkan terdapat beberapa pohon berdiameter $60 \mathrm{~cm}$ ke atas yang tidak dipanen karena gerowong, kayu keras dan terdapat beberapa jenis tidak ada pasaran kayu, pohon yang dilindungi dan pohon yang tidak bisa ditebang karena alasan keamanan baik bagi penebang maupun bagi kayu yang ditebang dan tegakan tinggal.

Berdasarkan uji beda rata-rata kerusakan tegakan tinggal yang terjadi akibat pemanenan kayu konvensional dan RIL menunjukkan kerusakan bahwa kerusakan tegakan tinggal akibat pemanenan kayu konvensional dan RIL berbeda sangat nyata pada tingkat kepercayaan $95 \%$.
Intensitas penebangan di hutan alam tropika di Asia dan Pasifik lebih tinggi di banding di wilayah lain (Putz et al., 2000). Pinard and Putz (1996) menyatakan bahwa rata-rata kerusakan tegakan di Sabah, Malaysia sebesar $154 \mathrm{~m}^{3} \mathrm{ha}^{-1}$. Thurland (1999) memperkirakan di Trengganu, Malaysia sebesar 80-125 $\mathrm{m}^{3} \mathrm{ha}^{-1}$. Elias (1998) mendapatkan hasil bahwa tingkat kerusakan tegakan tinggal yang disebabkan oleh pemanenan kayu konvensional berkisar antara 28-45\%, dimana kerusakan yang paling sering ditemukan adalah kerusakan berat (sekitar 80\%). Hal ini didukung oleh penelitian yang dilakukan oleh Sularso (1996) yang menyatakan bahwa di Kalimantan Timur kerusakan tegakan tinggal akibat pemanenan kayu konvensional dan RIL masing-masing sebesar $40.43 \%$ dan $19.08 \%$ dimana kerusakan yang terjadi berupa kerusakan berat (70-80\%).

\section{KESIMPULAN}

Kerusakan tegakan tinggal tingkat tiang dan pohon rata-rata per hektar akibat pemanenan kayu teknik konvensional dan RIL masing-masing sebesar 133.0 pohon $(33.15 \%)$ dan 83.3 pohon (19.53\%). Berdasarkan tingkat keparahannya, maka kerusakan yang terjadi pada petak pemanenan kayu konvensioal termasuk tingkat kerusakan sedang (25-50\%) dan pemanenan kayu RIL termasuk dalam tingkat kerusakan ringan $(<25 \%)$.

\section{UCAPAN TERIMA KASIH}

Kepada Prof. Dr. Ir. Elias yang telah membimbing dan memberi banyak pengetahuan kepada penulis. Kepada Ir. Ina Lidiawati, M.Si yang telah membantu penulis di lapangan.

\section{DAFTAR PUSTAKA}

Direktorat Jenderal Pengusahaan Hutan. 1993. Pedoman dan Petunjuk Teknis Tebang Pilih Tanam Indonesia (TPTI) pada Hutan Alam Daratan, Jakarta.

Dykstra, D.P. and R. Heinrich. 1996. Model Code of Forest Harvesting Practice. Food and 
Agriculture Organization of The United Nations, Rome.

Elias. 1997. State of The Art of Timber Harvesting Operations in The Tropical Natural Forest in Indonesia. Paper Presented on Exchange Meeting Between Staffts of Faculty of Forestry, Bogor Agricultural University, Bogor, Indonesia and Staffts of Shimane University, Japan 30 June 1997 in Shimane, Japan.

Elias. 1998. Forest Harvesting Case Study : Reduced Impact Timber Harvesting in the Tropical Natural Forest in Indonesia. FAO, Rome.

Holmes. 2000. Potret Keadaan Hutan Indonesia. Forest Watch Indonesia dan Washington D C Global Forest Watch. Bogor, Indonesia. Pinard, M.A., F.E. Putz, J. Tay and T.E. Sulivan. 1995. Development and Implementation of Timber Harvesting Guidelines. The Reduced Impact Logging in Sabah, Malaysia. Makalah disajikan dalam Workshop on Forestry Manpower Training in Jakarta, 26-27 Oktober 1995.

Pinard, M.A., and F.E. Putz. 1996. Retaining Forest Biomass by Reduced Logging Damage. BIOTROPICA, 28 (3) : 278-295.

Sukanda, A. 1998. Pemanenan yang Terencana dan Terkendali untuk Meminimalisasi Kerusakan Hutan di Wanareset Sangai, Kalimantan Tengah.

Sularso, H. 1996. Analisis Kerusakan Tegakan Tinggal Akibat Pemanenan Kayu Terkendali dan Konvesnional Pada Sistem Silvikultur Tebang Pilih Tanam Indonesia (TPTI). Tesis Pascasarjana IPB Bogor. (Tidak dipublikasikan).

Thurland, M. 1999. Environmental Analysis of Selective Logging and Extraction of Forest Residues. Technical Reports Volume 1, $p$. 214-296. Kuala Lumpur, Forest Department Peninsular Malaysia. 